\title{
A model-based flexural rotor vibration control in cage induction electrical machines by a built-in force actuator
}

\author{
Antti Laiho · Kari Tammi · Kai Zenger • \\ Antero Arkkio
}

Published online: 29 February 2008

(c) Springer-Verlag 2008

\section{Erratum to: Electr Eng}

\section{DOI 10.1007/s00202-007-0091-1}

The equation (15) is erroneous. The correct one is

$$
\begin{aligned}
\underline{f}_{\mathrm{c}}= & \frac{\pi d_{\mathrm{r}} l_{\mathrm{r}}}{4 \mu_{0} \delta_{0}}\left(1-\frac{1}{2} \delta_{p, 1}\right) \hat{B}_{p}^{2} \underline{z}_{\mathrm{r}} \\
& +\frac{\pi d_{\mathrm{r}} l_{\mathrm{r}}}{4 \delta_{0}}\left[k_{\mathrm{c}, p+1} \underline{B}_{p}^{*}\left|k_{\mathrm{r}, p-1} \underline{B}_{p}\right| k_{\mathrm{r}, p+1} \underline{B}_{p}^{*}\right] \\
& \times\left(\begin{array}{l}
\hat{\hat{i}}_{\mathrm{c}, p+1,0} \\
\hat{\hat{i}}_{\mathrm{r}, p-1,0}^{*} \\
\hat{i}_{\mathrm{r}, p+1,0}
\end{array}\right) .
\end{aligned}
$$

The numerical example presented in the paper was calculated for a two-pole $(p=1)$ machine for which the $p-1$-related terms were neglected. In this special case, the identification

The online version of the original article can be found under doi:10.1007/s00202-007-0091-1.

A. Laiho $(\varangle) \cdot$ K. Tammi

VTT Technical Research Centre of Finland,

P.O. Box 1000, 02044 VTT, Finland

e-mail: Antti.Laiho@vtt.fi

K. Tammi

e-mail: Kari.Tammi@vtt.fi

\section{K. Zenger}

Control Engineering Laboratory,

Helsinki University of Technology, 02015 TKK, Finland

e-mail: Kai.Zenger@tkk.fi

\section{A. Arkkio}

Laboratory of Electromechanics,

Helsinki University of Technology, 02015 TKK, Finland

e-mail: Antero.Arkkio@tkk.fi results in Table 2 are consistent with the corrected model when the estimated $\underline{B}_{p}$ is multiplied with $\sqrt{2}$ and $k_{\mathrm{c}, p+1}$ and $k_{\mathrm{r}, p+1}$ are multiplied by $1 / \sqrt{2}$. Under this scaling, the other equations in the paper remain unchanged. 